\title{
Poder local entre ora et labora: a casa beneditina nas tramas do Rio de Janeiro seiscentista ${ }^{1}$
}

Jorge Victor de Araújo Souza ${ }^{2}$

No começo do século XVII, os monges beneditinos se fixaram na América portuguesa. Os mosteiros adquiriram engenhos, escravaria, fazendas e imóveis nas áreas urbanas, por meio de reciprocidades com outros vassalos e instituições. O artigo aborda a inserção da instituição beneditina no Rio de Janeiro seiscentista e as relações estabelecidas para além do claustro, demonstrando o quanto a família monástica fazia parte da elite local.

Palavras-chave: Mosteiro de São Bento, inserções material e imaterial, elite religiosa.

Local power between ora et labora: the benedictine house in the plots of seventeenth-century Rio de Janeiro

In the early seventeenth century, the Benedictine monks settled in Portuguese America. The monasteries acquired plantations, slaves, farms and buildings in urban areas, through reciprocity with other vassals and institutions. The article discusses the inclusion of the Benedictine institution in seventeenth century Rio de Janeiro and the relationships beyond the cloister, demonstrating how the monastic family was part of the local elite.

Keywords: Saint Benedict's Monastery, material and immaterial insertion, religious elite

Pouvoir local entre ora et labora: la maison bénédictine dans le décor de Rio de Janeiro au XVIème siècle

Au début du XVIIème siècle, les moines bénédictins se fixèrent en Amérique portugaise. Les monastères acquirent des exploitations de canne à sucre, des esclaves, des fermes et

\footnotetext{
${ }^{1}$ Artigo recebido em 6/6/2011 e aprovado para publicação em 12/9/2011.

${ }^{2}$ Doutor e Pós-doutorando em história pela Universidade Federal Fluminense (UFF), professor da Universidade Severino Sombra (USS) e bolsista PDJ/CNPq.
} 
des biens immobiliers dans les zones urbaines, grâce à des échanges avec d'autres vassaux et institutions. L'article étudie l'insertion de l'institution bénédictine dans le Rio de Janeiro du XVIème siècle, ainsi que les relations établies hors du cloître, montrant à quel point la famille monastique faisait partie intégrante de l'élite locale.

Mots-clés: Monastère de São Bento, Insertion matérielle et immatérielle, Élite religieuse.

Um ponto nos surge claro e evidente: a ação criadora, e de modo nenhum parasitária, das grandes corporações religiosas - freires, cartuxos, alcobacenses, cistercienses de São Bernardo - na formação econômica de Portugal. Eles foram como que os verdadeiros antecessores dos grandes proprietários brasileiros.

FREYRE, Gilberto. Casa-grande \& Senzala.

Rio de Janeiro: Record, 2000. p. 295.

A observância das regras monásticas não apartava os monges de quaisquer cuidados ou negócios terrenos, pois bem sabiam como, na cidade dos homens, o ora não é separável do labora.

HOLANDA, Sérgio Buarque. Prefácio. In: Livro do Tombo do Mosteiro de São Bento da cidade de São Paulo. São Paulo:

Mosteiro de São Bento, 1977. p. XVIII.

Os monges de São Bento aportaram na América portuguesa ao final do século XVI graças a uma reforma ocorrida em sua Congregação e a deliberações na política filipina que visavam ao reequilíbrio dos poderes eclesiásticos nos territórios do Império português. Destarte, uma ordem milenar chegou aos trópicos no momento em que as bases institucionais no território estavam sendo estruturadas sob um acirrado processo de disputa por ocupação do solo. Inserções territorial e social eram faces de uma mesma moeda. Nesse sentido, os poderes locais foram elementos relevantes na fixação da ordem beneditina.

Em Portugal, sobretudo na região Norte, os mosteiros de São Bento constituíram casas que detinham poder local, por meio da administração de coutos e de influência política e jurídica. Além disso, seus membros eram selecionados entre a raia graúda da sociedade. A distinção de tais comunidades religiosas se dava sob várias maneiras, sendo as mais comuns por meio da antiguidade da ordem em território luso, da erudição dos religiosos, do nível de riqueza, das reciprocidades estabelecidas com elites e do perfil social de seus membros. Estes eram fatores constantemente relembrados pelos monges em suas disputas por privilé- 
gios, principalmente nos momentos de crise que assolaram a Ordem, como o do final do século XIV.

A réplica das casas monásticas do rincão minhoto era um ideal para os beneditinos na América portuguesa. No entanto, as peculiaridades da sociedade colonial logo se fizeram sentir - uma base econômica centrada na produção de açúcar, por sua vez assentada em uma sociedade escravista, que contava com vassalos em situações diferentes dos que se encontravam no centro -, demonstrando dessa forma, que uma simples transplantação institucional não seria incólume. Os mosteiros na América portuguesa enfrentaram problemas diferentes dos congêneres em Portugal, o que levou a diversas flexibilizações no sistema normativo da Congregação e a alianças com distintas instituições e outros vassalos. Ao longo da segunda metade do século XVII, tais diferenças da família monástica se apresentaram de forma mais contundente, por meio da reivindicação de alguns religiosos que almejaram o autogoverno das casas beneditinas da "Província do Brasil”.

Os beneditinos se instalaram na Bahia, Pernambuco, Paraíba, Rio de Janeiro e São Paulo, formando, entre abadias, priorados e presidências, 11 casas ao final do século XVII. O mosteiro de Salvador, o primeiro a ser fundado, em 1581, foi escolhido pelas autoridades monásticas como "cabeça" das demais casas, e assim permaneceu, senão de forma incisiva, pelo menos simbolicamente, até o início do século XIX. Entretanto, o mosteiro do Rio de Janeiro, seguindo a condição da capitania de um modo geral, teve um crescimento surpreendente, podendo ser considerado, em muitos aspectos - número de propriedades e escravaria, por exemplo -, tão ou mais opulento do que a casa beneditina em Salvador. Como reforçam as epígrafes retiradas de dois intérpretes do Brasil, uma instituição religiosa com essas características era possuidora de um específico poder local, gerado por dispositivos que a colocavam em interação com outros detentores de poderes.

\section{Territorialização, reciprocidades}

Os primeiros beneditinos que chegaram ao Rio de Janeiro, por volta de 1590, segundo crônicas da própria ordem, foram frei João Porcalho e frei Pedro de Ferraz. Ambos, naturais de Ilhéus e professos em Portugal. Nas narrativas beneditinas, são apontadas as habilidades dos dois religiosos ao obterem as doações iniciais. 
A primeira instalação de um mosteiro no Rio de Janeiro quinhentista ocorreu, em parte, graças à atuação de um vassalo de prestígio. Na localidade que foi denominada Prainha e que incluía um morro posteriormente chamado São Bento, Manuel de Brito e sua esposa doaram o terreno para que a ordem beneditina erguesse seu mosteiro. Em 1590, essa doação foi confirmada por Diogo de Brito, filho do casal.

$\mathrm{Na}$ formação de seu patrimônio, o mosteiro contou com uma variedade de bens doados. Em um primeiro momento, houve maior doação de terras, gados e escravos, ou seja, elementos necessários para montagem de fábricas de açúcar; e, posteriormente, durante maior intensidade na urbanização da capitania, o cenóbio recebeu vários imóveis e terrenos na área urbana. ${ }^{3}$

João Fragoso afirma que a primeira elite senhorial da capitania foi formada por descendentes de "conquistadores" e que esse grupo utilizou o fato para angariar prestígios. ${ }^{4}$ Os primeiros doadores de bens ao mosteiro saíram dessa elite e de seus descendentes. Entre doadores de terras para o mosteiro destaca-se Jorge Ferreira, conquistador do Rio de Janeiro ao lado de Estácio de Sá, cavaleiro fidalgo da Casa Real e capitão-mor de São Vicente. Em 1591, Jorge Ferreira doou aos beneditinos uma ilha no rio Iguaçu e mais 300 braças sertão adentro. Sua filha, a marquesa Ferreira, esposa de Cristóvão Monteiro, ouvidor da cidade entre 1568 e 1572, cavaleiro fidalgo da Casa Real e também um dos conquistadores do Rio de Janeiro, doou, em 1596, meia légua de terras em Iguaçu com fazenda, roças, pomares e casas de telhas. No final do século XVI e ao longo do XVII, o mosteiro recebeu constantes doações de pessoas "de qualidades elevadas". Em março de 1625, João de Moura Fogaça, capitão-mor, ouvidor-geral e lugar-tenente da condessa de Vimieiro, D. Mariana de Sousa da Guerra, donatária da capitania de São Vicente, doou ao mosteiro terras em Paraty. ${ }^{5}$ Sobre ele pesava suspeita de

\footnotetext{
${ }^{3}$ Para um mapeamento dos bens dos beneditinos no perímetro urbano, ver: FRIDMAN, Fania. Donos do Rio em nome do rei: uma história da cidade do Rio de Janeiro. Rio de Janeiro: Jorge Zahar/ Garamond, 1999. p. 55-82.

${ }^{4}$ Cf. FRAGOSO, João Luís Ribeiro. A nobreza da República: notas sobre a formação da primeira elite senhorial do Rio de Janeiro (séculos XVI e XVII). Topoi - Revista de História, Rio de Janeiro: PPGHIS/UFRJ, n. 1, p. 45-122, 2000.

${ }^{5}$ VI Livro do Tombo do Mosteiro de São Bento do Rio de Janeiro. Rio de Janeiro: Edições Lumen Christi, 1984. p. 242, 259 e 323. A partir daqui, referido como: VI LTMRJ.
} 
ser cristão-novo e, provavelmente, com sua doação buscava afastar essa macula, afirmando uma condição de bom católico. ${ }^{6}$

Já Belchior Tavares, que exercia o ofício de tabelião, doou, em 1612, duas léguas de terras perto do rio Guandu para que o mosteiro montasse currais de gado. ${ }^{7}$ Diogo Martins Mourão, casado com Francisca de Serrão Toar e filho de um dos fundadores da cidade, doou, em 1627, uma légua de terras em Maricá. ${ }^{8}$ Antonio Pinto, um dos sete capitães de Campos dos Goytacazes, e sua mulher, Margarida Baldes, doaram ao mosteiro, em 1646, metade de suas terras na região.

Alguns doadores pertenciam a elites e eram representantes da governança. ${ }^{9}$ Assim era traçada uma rede em torno do cenóbio. No corredor principal da igreja do mosteiro, bem em frente ao altar-mor, destacam-se duas tumbas, ambas com lajes brasonadas: "Sepultura da doadora Da. Vitoria de Sá - Falleceo aos 26 de agosto de 1667" e "Sepultura do doador Diogo de Brito de Lacerda e seus herdeiros”. Dona Vitória de Sá era sobrinha de Estácio de Sá e foi doadora ao mosteiro de todos os seus bens, incluindo um engenho; Diogo de Brito, como dito anteriormente, foi ninguém menos do que o doador do terreno onde está o mosteiro. Suas covas perpétuas são retribuições por suas importantes doações.

No dietário do abade frei Leão de São Bento, eleito em 1663, ficou registrado que "sobretudo soube este prelado granjear a devoção da Senhora D. Vitória de Sá, pela qual se aumentou consideravelmente o nosso patrimônio com a sua herança no triênio seguinte e só este serviço bastará para acreditar o seu grande zelo" ${ }^{10}$ Isso demonstra a necessidade e o reconhecimento de "certa habilidade"

\footnotetext{
${ }^{6}$ Ver genealogia de cristãos-novos em: SILVA, Lina Gorenstein Ferreira da. Heréticos e impuros: a Inquisição e os cristão-novos no Rio de Janeiro (século XVIII). Rio de Janeiro: Secretaria Municipal de Cultura/Departamento Geral de Documentação e Informação Cultural/Divisão de Editoração, 1995. p. 164.

${ }^{7}$ VI LTMRJ, p. 225 e 322.

${ }^{8}$ Ibid., p. 239.

${ }^{9}$ Entendemos o termo elite de acordo com algumas proposições gerais traçadas por Sebastián Molina Puche - nível de cabedal (patrimônio e rendas), influência na comunidade (mando), prestígio e participação em redes clientelares. Assim como Molina Puche, não consideramos esse grupo social como algo monolítico, por isso o uso da expressão "elites locais", na busca de salientar as diferenciações. PUCHE, S. Molina. Familia, poder y territorio: las elites locales del corregimiento de Chinchilla-Villena en el siglo XVII. Tese (Doutorado) - Universidad de Murcia, Murcia, 2005. p. 83-94.
}

${ }^{10}$ Dietário dos monges de São Bento. In: Mosteiro de São Bento do Rio de Janeiro: Abbadia Nullius de N.S do Monteserrate - o seu histórico desde a fundação até ao anno de 1927. Rio de Janeiro: 
dos prelados para adquirirem doações importantes, por meio de suas relações pessoais. Nos dados de sua administração, temos a informação de que o beneditino "fazia contas com Dona Vitória de Sá", que, ao que parece possuía negócios com o mosteiro, mais precisamente com a venda de açúcar.

Frei Leão de São Bento era testamenteiro de D. Vitória de Sá. No testamento, feito em 30 de janeiro de 1667, são perceptíveis as relações existentes entre o mosteiro e essa representante dos "conquistadores" do Rio de Janeiro. Vitória de Sá era filha de Gonçalo Correia de Sá, irmão de Martim de Sá, ambos filhos de Salvador Correia de Sá, "O Velho", um dos fundadores da cidade do Rio de Janeiro e dono de engenhos. Era prima de Salvador Correia de Sá e Benevides, governador do Rio de Janeiro e importante personagem nas tramas atlânticas. Vitória de Sá, em 1630, casou-se com Luis de Céspedes y Xeria, nomeado governador do Paraguai. Segundo Charles Boxer, a família Sá tinha muito a ganhar aliando-se a um "pobretão", pois este assumira o governo de uma região comercialmente estratégica. ${ }^{11}$ A importância da aliança é demonstrada pelo esforço que fez Salvador de Sá em acompanhar sua prima até Assunção para que ocorresse o dito enlace.

No documento em que dispõe seu legado aos beneditinos como únicos herdeiros, já que não teve filhos com o espanhol, podem-se vislumbrar a pujança da "benfeitora" e a extensão dos bens que seus familiares transmitiram. Dona Vitória deixou aos religiosos quatro casas de pedra e cal, coladas às dos governadores, um engenho em Camorim, com igreja, vivenda de sobrado e todos os materiais necessários para a fabricação de açúcar, assim como escravos da Guiné, crioulos e "gente da terra". Deixou, também, três currais de gado com 100 cabeças e algumas ovelhas, além de "terras desde o rio Pavuna até o mar e correndo a costa até junto da Guanabara com seus montes, campos, restingas, lagoas e rios", que dizia ter herdado dos pais e dos avós. ${ }^{12}$

$\mathrm{O}$ ato de "bem morrer" era uma preocupação constante na América portuguesa e contribuía para o aumento dos bens das instituições eclesiásticas. Testar

\footnotetext{
[s.n.], 1927. p. 31-32. A partir daqui, referido como Dietário/RJ.

${ }^{11}$ BOXER, Charles. Salvador de Sá e a luta pelo Brasil e Angola, 1602-1686. São Paulo: Nacional/Ed. Da Universidade de São Paulo, 1973. p. 97.

${ }^{12}$ Arquivo do Mosteiro de São Bento do Rio de Janeiro (AMSBRJ). Doc. 1411-13. Testamento de D. Vitória de Sá, 30 de janeiro de 1667. Transcrito em: SILVA-NIGRA, Clemente Maria da. Construtores e artistas do Mosteiro de São Bento do Rio de Janeiro. Salvador: Typografia Beneditina, 1950. p. $249^{\star}-258^{\star}$.
} 
era uma forma especial de doação. No arquivo do mosteiro, encontram-se testamentos que apontam o desejo dos fiéis em serem amortalhados com o hábito beneditino. Em um dos mais antigos, datado de 1616, Francisco Jacome pede que os religiosos de São Bento "mandem amortalhá-lo no hábito da dita ordem” e o "enterrem no dito mosteiro". ${ }^{13}$ Já o capitão Manoel Fernandes Franco exigiu que seu corpo fosse sepultado no mosteiro, onde dizia ter uma sepultura, e completou: "peço aos religiosos do dito mosteiro me façam aquelas honras a meu corpo e sufrágios a minha alma na forma que temos contratado por uma escritura de doação que fiz quando lhe dei meu engenho". ${ }^{14} \mathrm{O}$ dito engenho, doado em 4 de maio de 1695, ficava na Ilha do Governador. Manoel Fernandes e sua esposa, Cecília de Siqueira, não tiveram filhos. Cecília era filha de Baltazar Leitão e prima de Cristóvão Lopes Leitão, o que a ligava ao filho deste, frei Cristóvão de Cristo, três vezes abade do mosteiro do Rio de Janeiro.

É preciso salientar que o clero, principalmente o regular, era detentor de mecanismos propícios para a guarda e os usos da memória das comunidades. A tradição é muito antiga. Cozroh, um compilador do século IX, afirma em um prefácio do Cartulário de Freising que sua intenção era manter "a lembrança dos que enriqueceram esta casa [mosteiro] com seus bens e fizeram-na sua herdeira, permaneça para sempre, assim como tudo o que eles entregaram e deram a esta casa pela salvação de suas almas" ${ }^{15}$ Patrick Geary, medievalista, nos ajuda a entender determinados processos nas ligações entre a "especialização da memorialística" e os comportamentos dos monges, afirmando que tal processo "implicava uma relação estreita entre a lembrança das doações e os necrológios nos quais se evocava a memória dos doadores" ${ }^{16} \mathrm{Na}$ afirmação de Geary, percebemos que a memória monástica não era estática, mas estava em constante formulação e recriação; característica que notamos, também, nos casos dos mosteiros na América portuguesa.

Cobrindo o período entre 1654 e 1793, é possível contabilizar 36 heranças de monges que foram consideradas significativas pela própria comunidade religiosa

\footnotetext{
${ }^{13}$ AMSBRJ. Doc. 856-4. Testamento de Francisco Jacome.

${ }^{14}$ AMSBRJ. Doc. 872-10. Testamento de Manoel Fernandes Franco.

${ }^{15}$ COZROH Apud GEARY, Patrick. Memória. In: LE GOFF, Jacques; SCHMITT, Jean Claude (Orgs.). Dicionário temático do Ocidente Medieval. Bauru: Edusc, 2006. v. II, p. 170. 16 Ibid., p. 171.
} 
do Rio de Janeiro. Outros bens eram transmitidos, mas não eram considerados tão expressivos, como garfos de prata, livros, tecidos e alguns objetos de uso pessoal. Bens dessa monta eram leiloados entre os próprios monges.

O mosteiro angariou preciosos bens com a entrada de frei Francisco de Jesus Vilalobos na Ordem. Nascido na mesma capitania e filho de André da Silveira Vilalobos e Isabel de Souto Maior, "nobres pelas suas famílias", frei Francisco já tinha sido sacerdote secular e jesuíta antes de procurar os beneditinos, em 1665. Ao entrar no mosteiro, fez um testamento entregando à instituição tudo o que possuía: "um bom partido na Pavuna, perto de Camorim, com trinta escravos e quatro moradas de casas na cidade e muita prata que se aplicou para a sacristia". ${ }^{17}$ Ele cumpria o que rege a Regra em seu capítulo 59, na determinação dada aos que estão chegando: "façam a doação das coisas que querem dar ao mosteiro". ${ }^{18}$ No entanto, frei Francisco não esqueceu seus parentes, a quem deixou uma casa de sobrado na rua Direita e pensão de missas rezadas na igreja do mosteiro. ${ }^{19}$

Frei Cristóvão de Cristo, natural do Rio de Janeiro e filho de pais "nobres, ricos e virtuosos", morreu em 1716, com 75 anos de idade. O mosteiro recebeu da legítima de seus pais aproximadamente 5:700\$000, uma quantia extraordinária, contando com um engenho de nome Moriquipari, que foi vendido posteriormente. ${ }^{20}$ Outro monge que contribuiu de forma generosa para o patrimônio do mosteiro foi frei Jacinto da Trindade, descendente dos "nobres dos mais distintos da terra". Professou no Rio de Janeiro, no ano 1664. Tornou-se mestre de noviços e administrador das fazendas de Campos, Maricá e Vargem. O mosteiro recebeu seu espólio em 1721, que contava com terras em Maricá, chamadas Barras Vermelhas, e um curral de gado em Campos dos Goytacazes. ${ }^{21}$ As primeiras formas de aquisições, baseadas, sobretudo, em reciprocidades, possibilitaram a inserção da Ordem nos negócios agrários, contando, inclusive, com considerável escravaria.

\footnotetext{
${ }^{17}$ AMSBRJ. Testamento 951-4. Transcrito em: SILVA-NIGRA (1950). Op. cit., p. 259*.

${ }^{18}$ A regra de São Bento. Rio de Janeiro: Lumen Christi, 2003. p. 127.

${ }^{19}$ Dietário/RJ, p. 139.

${ }^{20}$ Ibid., p. 148.

${ }^{21}$ Ibid., p. 152.
} 


\section{Senhor de almas, dono de pastos e engenhos}

A historiografia brasileira tem tratado cada vez mais da constituição da família escrava no Brasil. Entretanto, as pesquisas estão concentradas nos plantéis do final do século XVIII e, principalmente, nos do século XIX. Os historiadores que se dedicam à temática são unânimes em salientar a dificuldade de se encontrar documentação para períodos anteriores a esses. ${ }^{22}$

Para os plantéis da Ordem de São Bento, pelo menos nas propriedades do Rio de Janeiro, é destacável a presença da formação de famílias escravas desde meados do século XVII, precisamente nos estados que cobrem os anos 1648 a 1660. Isso é perceptível, por exemplo, na documentação referente a 1652, quando o monge que registrava os bens do mosteiro deixou anotado que na fazenda de Inhumerim ficaram 26 escravos. ${ }^{23}$ Ao todo, essa propriedade contava com nove casais e dois viúvos, ou seja, mais da metade da escravaria havia contraído matrimônio. Logo abaixo de seus nomes foram contabilizadas 11 crianças, o que aponta a reprodução dos cativos.

Nos currais de Maricá ficavam 17 escravos, tomando conta de 275 cabeças de gado, sendo casais "Diogo e sua mulher, Manuel e sua mulher, Jorge e sua mulher, cinco filhos de Diogo e duas filhas, filho de Jorge de doze anos". ${ }^{24}$ Nos anos subsequentes, ficam mais perceptíveis numerosas alianças matrimoniais ocorrendo entre os escravos e a consequente reprodução endógena.

Em 1657, a fazenda de Campos dos Goytacazes é indicada como a mais próspera, pois possuía 8.631 cabeças de gado, distribuídas em 20 currais. Entre adultos e crianças, existiam 74 escravos espalhados pelos mesmos currais. A população adulta era de 48 cativos, e, destes, 42 eram casados e dois, viúvos. A relação apresenta casais com respectivos filhos, como Manoel crioulo e sua mulher Úrsula e quatro filhos, Alexandre e sua mulher Vitória e duas filhas, João Rato e sua mulher Serafina e seus dois filhos. A maneira como era contabilizada a escravaria denota a reprodução endógena, pois, ao tratar das crianças, o monge

\footnotetext{
${ }^{22}$ SLENNES, Robert. Na senzala, uma flor: esperanças e recordações da família escrava. Brasil, Sudeste, século XIX. Rio de Janeiro: Nova Fronteira, 2000; FLORENTINO, Manolo; GÓES, José Roberto. A paz das senzalas; famílias escravas e tráfico atlântico, Rio de Janeiro, c. 1790-c. 1850. Rio de Janeiro: Civilização Brasileira, 1997.

${ }^{23}$ Arquivo Distrital de Braga/Congregação de São Bento (ADB-CSB) 134, p. 32.

${ }^{24} I d$.
} 
anotou: "crias macho 10, crias fêmeas 14 ". ${ }^{25}$ Três anos depois, o número de cativos era de 89. Mantinha-se a tendência de se ter um equilíbrio entre homens e mulheres e casais, sendo no total 23. Infelizmente, o número de crianças por casal não é especificado como na relação anterior. No entanto, ficou registrado que sete casais possuíam filhos. Nesse mesmo período, no engenho de Guaguaçu, ao fundo da Baía da Guanabara, encontrava-se um número semelhante de escravos. O monge que fez a anotação deixou escapar um interessante deslize: "ficam neste engenho noventa peças, digo, almas de escravos". ${ }^{26} \mathrm{O}$ lapso corresponde ao tratamento cristão que deveria ser dispensado ao cativo - almas, e não peças -, haja vista tratar-se do plantel de uma ordem religiosa. ${ }^{27}$ Acompanhando a tendência observada, dos 90, 34 eram casados. É confirmada a presença de crianças, mesmo que o número não seja especificado, contabilizando-se, inclusive, filhos de solteiros. A tendência do equilíbrio da quantidade de homens e mulheres formando casais pode ser vista em outras duas propriedades: Cabo Frio, com sete currais, contabilizando 483 cabeças de gado e seis casais de escravos, exatamente a metade dos escravos da propriedade; e os currais de Maricá, com 319 cabeças de gado e quatro casais de escravos com seus filhos. ${ }^{28}$

O costume de os monges estadistas detalharem a composição da escravaria, infelizmente, durou pouco. Todavia, de forma menos minudenciada, temos dados do Estado, de 1663 a 1666, durante o abaciado de frei Leão de São Bento, o último a fornecer a quantidade de escravos. Nesse relatório, ficou registrada a compra de 27 cativos e o recebimento de 30 "peças" de heranças. É possível perceber que o engenho de Guaguaçu aumentou o número de escravos para 115, sendo 33 "crias", assim como a fazenda de Campos, com 106 cativos em seus currais. ${ }^{29}$

\footnotetext{
${ }^{25}$ ADB-CSB 134, p. 56.

${ }^{26}$ Ibid., p. 75.

${ }^{27}$ Sobre a forma cristã em que a escravidão foi enquadrada, ver: VAINFAS, Ronaldo. Ideologia e escravidão; os letrados e a sociedade escravista no Brasil colonial. Petrópolis: Vozes, 1986; MARQUESE, Rafael de Bivar. Feitores do corpo, missionários da mente: senhores, letrados e o controle de escravos nas Américas, 1660-1680. São Paulo: Companhia das Letras, 2004; ZERON, Carlos Alberto de Moura Ribeiro. La Compagnie de Jésus et l'institution de l'esclavage au Brésil: les justifications d'ordre historique, théologique et juridique, et leur intégration par une mémoire historique (XVIe-XVIIe siècles). Tese (Doutorado) - École des Hautes Études en Sciences Sociales, Paris, 1998. $559 \mathrm{f}$.
}

${ }^{28}$ ADB-CSB 134, p. 55.

${ }^{29}$ ADB-CSB 134, p. 96-97. 
De acordo com Schwartz, os beneditinos incentivaram o equilíbrio numérico dos sexos e a conformação familiar no intuito de promover uma política moralizante, mas também como uma estratégia significativa, haja vista que o vínculo instituído pela família inibia fugas e indisciplinas. ${ }^{30}$ Há uma característica importante a ser assinalada no que diz respeito a essas famílias: os núcleos de escravos casados e os respectivos descendentes gerados encontravam-se, sobretudo, no trabalho em currais de gado. Pela manutenção tão prolongada da constituição de famílias em currais, pode-se inferir que os beneditinos, mais do que o uso de feitores escravos, souberam tirar proveito da fixação de grupos familiares nas áreas de criação de gado.

No importante engenho de Iguaçu, nos serviços braçais do eito também havia um equilíbrio de gêneros entre os cativos. No inventário realizado na "entrega que fez o padre frei Francisco das Chagas da fazenda do Iguaçu ao padre frei Rozendo do Rosário na era de 1685", foram registrados 48 cativos, sendo 27 do sexo feminino e 21 do masculino. ${ }^{31}$ Gentios da terra não estão registrados. Isso não significa que os beneditinos abriram mão desse tipo de cativo, mas que em suas fazendas começavam a prevalecer o africano e seus descendentes. Ao lado dos nomes arrolados foram registradas as ferramentas utilizadas pelos escravos, apontando, assim, suas respectivas funções, entre eles: Isabel de enxada e foice, Suzana de enxada e André de machado e foice. Somente dois cativos tinham um ofício mais especializado: os mulatos Thomas e Romano, ambos carpinteiros.

Segundo João Fragoso, a economia no Rio de Janeiro, gerada a partir da produção da cana-de-açúcar, era "esquisita", pois se baseava em engenhos de segunda categoria. O açúcar da capitania estaria sob "uma blindagem diante dos desassossegos do mercado internacional", ou seja, os preços mantinham-se de forma artificial, com forte dependência dos desígnios políticos. ${ }^{32}$ Nessa chave interpre-

${ }^{30}$ SCHWARTZ, Stuart B. Segredos internos: engenhos e escravos na sociedade colonial, 1550-1835. São Paulo: Companhia das Letras, 1995. p. 293.

${ }^{31}$ Em 1943, quando transcreveu o documento, D. Clemente salientou que ele estava "quase aniquilado pela traça". Infelizmente, ao empreendermos pesquisa no Arquivo do Mosteiro do Rio de Janeiro não foi possível encontrar tal fonte, cumprindo-se o que foi preconizado pelo beneditino. SILVA-NIGRA, D. Clemente Maria da. A antiga fazenda de São Bento em Iguaçú. Revista do SPHAN, Rio de Janeiro, n. 7, p. 269-270, 1943.

${ }^{32}$ FRAGOSO, João. Fidalgos e parentes de pretos: notas sobre a nobreza principal da terra no Rio de Janeiro (1600-1750). In: FRAGOSO, João Luís Ribeiro; ALMEIDA, Carla Maria Carvalho de, SAMPAIO, Antônio Carlos Jucá de (Orgs.). Conquistadores e negociantes: histórias de elites no 
tativa, Fragoso aponta a importância das relações e dos vínculos que eram estabelecidos em torno da produção açucareira, em que "o engenho consistia de fato numa mercadoria especial, pois podia ser suporte de relações clientelares e de parentesco fictício entre senhores, lavradores, forros e escravos: leia-se de finas negociações entre diferentes estratos da sociedade dita sociedade americana". ${ }^{33}$ Seria esse quadro também tecido pelos engenhos beneditinos da capitania?

No Rio de Janeiro, os beneditinos possuíram engenhos em Campos dos Goytacazes, Ilha do Governador, Iguaçu, Camorim e Vargem. Nos registros dos estados nem sempre ficaram pormenorizados os dados referentes à produção canavieira de cada fazenda. Ao trabalhar com esses registros, é preciso levar em consideração que o definido como "triênio", na administração de um abade, não correspondia necessariamente ao período de exatos três anos. Alguns registros dizem respeito apenas a um ano. Além disso, existem lacunas entre os registros, e alguns triênios simplesmente não aparecem na contabilidade, apesar da punição que pairava sobre o abade que não a enviasse para Portugal. Luis Lizanti formulou tabelas com os dados sobre os rendimentos do mosteiro entre 1620 e 1793 e concluiu que a cana-de-açúcar era o produto mais relevante nas receitas dos beneditinos. ${ }^{34}$

Entre 1620 e 1623, início da contabilidade, ou pelo menos o registro mais antigo encontrado, o açúcar respondia por 55,3\% dos rendimentos, colocando $872 \$ 990$ nos cofres beneditinos, sendo o restante obtido com a criação de gado, nos foros, na sacristia e nos subsídios da Coroa, que nesse período cobriram apenas $10,1 \%$ da receita, entre outras entradas. A participação do açúcar na economia beneditina do Rio de Janeiro sofreu várias flutuações, mas manteve-se relevante durante dois séculos. Outras formas de rendimentos sobrepujaram a participação do açúcar na contabilidade beneditina, mas, no final do século XVIII, o produto ainda tinha fôlego para ser responsável por 32,5\% da receita, depositando nos cofres dos monges o apreciável valor de $22.529 \$ 575$.

Antigo Regime nos trópicos. América lusa, séculos XVI a XVIII. Rio de Janeiro: Civilização Brasileira, 2007. p. 101.

${ }^{33}$ Ibid., p. 103.

${ }^{34}$ LISANTI, Luis. Estratégia de gestão: um exemplo, Rio de Janeiro 1620/1793. Estudos Econômicos, Departamento de Economia da Faculdade de Economia, Administração e Contabilidade da Universidade de São Paulo, n. 13, p. 763-769, 1983. 
O primeiro e principal engenho dos beneditinos no Rio de Janeiro foi o de Iguaçu, construído entre 1613 e 1616, durante o abaciado de frei Bernardino de Oliveira, monge oriundo de Lisboa e que já tinha sido procurador do mosteiro de Salvador entre 1609 e 1612, sendo, portanto, um religioso que entendia dos negócios da Ordem. Mas foi durante o abaciado anterior, de frei Ruperto de Jesus, natural de Lisboa e abade do mosteiro do Rio de Janeiro em 1600, amigo do governador Francisco de Souza, que as propriedades foram adquiridas. Do capitão Afonso de Albuquerque, conseguiu, em 7 de junho de 1611, "as pontas e voltas do rio Iguaçu com os sobejos que houvessem”, com muitas lenhas e madeiras. ${ }^{35}$ Dando prosseguimento à estratégia de montar um engenho na região, comprou de Tomé de Alvarenga e sua mulher 750 braças de testada com 1.200 de comprimento, em 18 de abril de 1613 , por $110 \$ 000 .^{36}$

Foi possível, por meio do dietário do Rio de Janeiro, identificar 24 monges atuando na administração de fazendas e engenhos. Um deles laborou na fazenda Iguaçu e também no engenho das Lages na Bahia, apontando que havia a possibilidade de um monge, nessa ocupação, ter experiências em locais variados na América portuguesa. Chamava-se frei Manoel da Luz, nascido em São João da Foz, no bispado do Porto, e noviço na Bahia em 1676. Ocupou o cargo de companheiro e secretário do provincial, prior, procurador-geral da Congregação, e morreu no Rio de Janeiro com idade bem avançada em $1743 .{ }^{37}$

Nos "estados", só temos informações relativas a cinco triênios para o século XVII, e assim mesmo cobrindo de forma espaçada os anos de 1620 a 1666. Mas, como observou Luis Lisanti, são dados suficientes para perceber a importância da produção de açúcar na receita dos religiosos. ${ }^{38}$ Entre 1648 e 1652, o valor obtido com o açúcar foi de 5.905\$100, suficiente para saldar as dívidas contraídas. No abaciado seguinte, entre 1652 e 1657, o mosteiro conseguiu angariar 7.562\$733, valor bem superior aos $2.970 \$ 290$ ganhos com a criação de gado. Todavia, mesmo sendo uma quantia significativa, a produção ficava bem abaixo da conseguida pelo mosteiro da Bahia no mesmo período, atingindo mais de 40.000\$000 em seu engenho de Lages. Essa diferença não deve ser atribuída a uma pecu-

\footnotetext{
${ }^{35}$ IV LTMRJ, p. 237.

${ }^{36}$ Ibid., p. 238.

${ }^{37}$ Dietário/RJ, p. 165.

${ }^{38}$ LISANTI (1983). Op. cit.
} 
liaridade da administração beneditina, mas à conjuntura de uma maneira mais ampla, incluindo a qualidade do açúcar no Rio de Janeiro e sua inserção no mercado atlântico. ${ }^{39}$ Adentrando o século XVIII, paulatinamente o valor do açúcar na receita dos beneditinos foi sendo superado pelo valor dos aluguéis de casas, mas os religiosos continuaram investindo em seus engenhos, demonstrando que outros valores, além do monetário, eram também significativos. Os religiosos eram senhores de engenhos - sem dúvida, um aspecto aristocratizante.

O escoamento da produção açucareira provocava outras situações de vínculos entre os beneditinos e os membros das elites locais. Eram transações que envolviam alta confiabilidade por parte dos religiosos e grande disponibilidade dos proprietários de embarcações. Não foi relatado o quanto tais proprietários lucravam com o frete do nobre produto.

Entre 1620 e 1623, os monges embarcaram 90 arrobas de açúcar branco e 108 de mascavado na caravela de Domingos Franco. No mesmo período, 45 arrobas de branco e 32 de mascavado foram embarcadas na nau de Gonçalo Ramos, e João Maris Negrão levou para Lisboa 63 arrobas de branco e 16 de mascavado. A estratégia era embarcar a produção em maior número possível de embarcações, não arriscando a concentração em uma única nau. Sinistros podiam ocorrer. No mesmo documento, foi anotado que as 50 arrobas de branco e 51 de mascavado que levava a nau de Francisco Luis foram roubadas por holandeses. Tais transações apontam a riqueza da casa monástica.

Atentando para a situação da Igreja na Espanha moderna, Maximilliano Barrio salientou o quanto uma aproximação do nível de riqueza do clero é algo difícil de detalhar. Incontestável é o fato de que as rendas das ordens religiosas eram elevadas. ${ }^{40} \mathrm{O}$ mesmo, guardando as devidas peculiaridades, podemos estender aos mosteiros da América portuguesa. Apesar da dificuldade em mensurar com exatidão as extensões de suas propriedades, a quantidade de seus cativos, o alcance de sua rede creditícia e as rendas adquiridas por meio dos bens urbanos e rurais,

\footnotetext{
${ }^{39}$ As diferenças entre os embarques do açúcar, no começo do século XVII, podem ser verificadas em: SAMPAIO, Antônio Carlos Jucá de. A produção política da economia: formas não-mercantis de acumulação e transmissão de riqueza numa sociedade colonial (Rio de Janeiro, 1650-1750). Topoi: Revista de História. Rio de Janeiro: Programa de Pós-Graduação em História Social da UFRJ/7 Letras, v .4, n. 7, p. 276-312, 2004; p. 65, jul./dez. 2003.

${ }^{40}$ GONZALO, Maximiliano Barrio. El clero en la España Moderna. Córdoba: CSIC/Cajasur, 2010. p. 57.
} 
podemos afirmar que a instituição beneditina legou uma documentação em que seu nível de riqueza, de forma generalizada, pode ser considerado alto. Havia renda suficiente para sustentar uma família que tinha em média 40 membros, fora cativos e empregados.

\section{Um perfil da família}

Apesar de o sistema normativo dos beneditinos apresentar uma clivagem determinada, baseada principalmente na origem familiar, ser "bem-nascido" não era sempre uma garantia de fácil acesso aos quadros da Ordem. É o que se nota na correspondência das autoridades em 26 de novembro de 1722, quando "o rei fica sabendo que os beneditinos não aceitam nascidos na terra senão com as cláusulas de que os seus pais contribuam com um donativo tão numeroso que chega a ser um bom dote de freira". ${ }^{41}$ Em 1744, as queixas continuaram a chegar. Em carta da Câmara, fica-se a par "dos abusos praticados pelos monges de São Bento naquela cidade, exigindo dinheiro como dote dos filhos dos fiéis que pretendiam ingressar no serviço religioso". 42 A reciprocidade entre os religiosos e os ocupantes da Câmara não estava funcionando. Os camaristas recordaram aos beneditinos que, durante a instalação de sua Ordem na cidade, contaram com os cabedais e as esmolas dos moradores e que suas imensas propriedades se deviam a isso; em contrapartida, afirmavam que os religiosos deveriam garantir "cômodo para os seus filhos, netos e parentes". ${ }^{3}$

Para o mosteiro do Rio de Janeiro, no século XVIII, de um total de 83 monges, conseguimos identificar a naturalidade de 75 , e, desse universo, $66 \%$ nasceram na América portuguesa. Esses dados, pelo menos em parte, põem em xeque as constantes reclamações feitas pela Câmara do Rio de Janeiro, que acusava o mosteiro de dar preferência aos "nascidos em Portugal". No século XVII, a metade dos 48 noviços era nascida na América portuguesa.

Nos registros que fazem referências aos monges, há várias indicações de que parte significativa dos candidatos provinha das "melhores famílias da terra". As marcas de distinção aparecem nos qualificativos salientados no núcleo parental

\footnotetext{
${ }^{41}$ AHU-RJ. CX 13. Doc. 134. 26 de novembro de 1722.

${ }^{42}$ AHU-RJ CX 43. Doc. 89.7 de novembro de 1744.

${ }^{43} \mathrm{Id}$.
} 
do candidato. Jacinto da Trindade, natural do Rio de Janeiro e falecido em 1721, era filho do capitão João Correa da Silva e de Elena da Silva Cabral, "ambos ricos, nobres e dos mais distintos desta terra". ${ }^{44}$ Outro candidato, João de Azevedo, também natural do Rio e professo em 1689, tinha "pais ricos e distintos". ${ }^{45}$ Caetano César Leite era de uma das "principais famílias" da Vila de Santos. ${ }^{46}$

Frei João de Sant'Ana de Sousa, nascido no Rio de Janeiro em 1644, era filho dos "principais da terra" Pedro de Sousa Pereira e Ana Correia, aparentada com a importante família Correia de Sá. A estratégia familiar do monge foi a mesma de boa parte das "pessoas de qualidade" da sociedade de então. O irmão mais velho, que "ficou por cabeça do casal", possuía o mesmo nome de seu pai e ocupou o mesmo cargo - provedor da Fazenda Real. As irmãs foram enviadas para o convento de Santa Clara.

Ao entrar para o mosteiro do Rio de Janeiro em 3 de junho de 1659, frei João contou com alguns membros dos "melhores da terra" entre suas testemunhas, asseverando que as relações de sua família eram de muito prestígio. Nesse dia, foram ao mosteiro: o padre Pedro Homem Albernaz, prelado administrador da diocese, com 86 anos; o capitão Aleixo Manuel, filho do fundador da antiga ermida onde o mosteiro foi construído, com 84 anos; Constantino Cardoso, de quem não foi possível apurar informações; e Pedro de Souza Brito, capitão-mor de Cabo Frio, com então 50 anos. ${ }^{47}$ Eram pessoas "antigas e qualificadas" que ajudaram em sua entrada na Ordem. Frei João tornou-se abade do mosteiro da Bahia em 1676 e procurador da Ordem em Roma em 1679.

A estratégia de manter um filho como "cabeça do casal" na expectativa de perpetuação da família e de seu prestígio não funcionou para o núcleo familiar de frei João de Sant’Ana. Seu irmão, Pedro de Sousa Pereira, comprou dos beneditinos parte do cabedal que seus pais deixaram. Era homem de grande prestígio e influência na capitania, dono de engenhos de três moendas. Não se casou e nem teve filhos. ${ }^{48} \mathrm{~A}$ perpetuação do núcleo de sua família anulou-se, quando foi assas-

\footnotetext{
${ }^{44}$ Dietário/RJ, p. 152.

${ }^{45}$ Ibid., p. 178.

${ }^{46}$ Ibid., p. 171.

${ }^{47}$ AMSBRJ. Pasta das inquirições. Inquirição no 24 (Frei João de Sant’Ana de Sousa).

${ }^{48}$ AMSBRJ. Doc. 942-6. Testamento de Pedro de Souza Pereira.
} 
sinado em maio de $1688 .{ }^{49} \mathrm{O}$ restante da família, ao menos em tese, por conta dos votos religiosos, não poderia produzir rebentos.

Os noviços são distinguidos como pertencentes ao topo da hierarquia social. A "existência de um conjunto de instituições eclesiásticas indispensáveis aos modelos de reprodução das casas nobiliárquicas" é destacada pelo historiador Nuno Gonçalo Monteiro como uma das características do Antigo Regime em Portugal..$^{50}$ Ao que parece, buscou-se manter a tradição na América portuguesa, mesmo quando os pretendentes não eram descendentes dos Grandes do Reino. Apesar da impossibilidade de uma análise seriada das origens sociais dos noviços, é perceptível a "qualidade" dos membros da ordem beneditina. Tal condição era ressaltada nas disputas com outros vassalos e instituições.

\section{Senhores daqueles campos}

Em um período em que predominava a indiferenciação entre o público e o privado, com a circulação de documentos por vezes forjados, as alianças de "bandos" facilitavam a posse da terra. Doações, vendas e trocas de terras foram motivos de contestações e de disputas acirradas. Talvez o caso mais controverso na capitania do Rio de Janeiro tenha sido o mito fundador da região dos Campos dos Goytacazes, em que os beneditinos, assim como os jesuítas, estiveram envolvidos. ${ }^{51} \mathrm{O}$ caso dos "sete capitães" é, até os dias atuais, descrito como a injustiça que os primeiros exploradores da atual região norte fluminense sofreram nas mãos do governador Salvador Correia de Sá e Benevides.

\footnotetext{
${ }^{49}$ AHU-RJ. Doc. 367. 22 de maio de 1688. Carta do ouvidor-geral do Rio de Janeiro, Thomé de Almeida e Oliveira, em que participa o assassinato de Pedro de Sousa Pereira e as diligências que empregara para prender os criminosos.

${ }^{50}$ MONTEIRO, Nuno Gonçalo. O crepúsculo dos grandes: a casa e o patrimônio da aristocracia em Portugal (1750-1832). Lisboa: Imprensa Nacional, 2003. p. 143.

${ }^{51}$ Outro exemplo de contendas por terras envolvendo os monges de São Bento ocorreu em 1626, quando Manuel de Araújo Aragão nomeou seu tio, o padre João Araújo de Aragão, seu procurador para demarcar terras em que os beneditinos pretendiam fazer um engenho. AHU-BA. Luiza da Fonseca. 4 de abril de 1626, Lisboa.
} 
Os "sete capitães", Miguel Aires Maldonado, ${ }^{52}$ João de Castilho Pinto, ${ }^{53}$ Antonio Pinto Pereira, ${ }^{54}$ Miguel Vaz Riscado, ${ }^{55}$ Duarte Correia Vasqueanes, ${ }^{56}$ Manuel Correia ${ }^{57}$ e Gonçalo Correia de Sá ${ }^{58}$ pediram ao governador, em 1627, um enorme trecho de terras cobrindo parte de Cabo Frio até o extremo de Campos dos Goytacazes. O pedido coletivo buscava mercês por serviços prestados à Coroa, principalmente o extermínio/a expulsão de índios e a defesa contra os "invasores estrangeiros". Os solicitantes alegaram que tinham mais de 20 anos de prestação de serviços. Por determinação do governador Martim de Sá, os sete foram remunerados com as terras solicitadas em 19 de agosto de 1627.

Apesar de terem alcançado uma mercê, a posse dos "sete capitães" foi contestada por Salvador Correia de Sá e Benevides. ${ }^{59}$ Como salientou Charles Boxer, "não padece dúvida que a redistribuição efetuada em 9 de março de 1648 trouxe

\footnotetext{
${ }^{52}$ De origem espanhola, nasceu nas Ilhas Canárias. Chegou ao Rio de Janeiro em 1613 e morreu na mesma capitania no ano 1650. Foi camarista e dono de currais de gado na região de Quissamã, engenhos de açúcar na Tijuca e Ilha do Governador. Em 1633, casou-se com Bárbara Pinto de Castilho. Lutou contra os holandeses e recebeu o hábito de São Bento de Avis em 1646. Também foi provedor da Santa Casa de Misericórdia entre 1643 e 1644. BELCHIOR, Elysio de Oliveira. Conquistadores e povoadores do Rio de Janeiro. Rio de Janeiro: Livraria Brasiliana Editora, 1965. p. 303-306.

${ }^{53}$ Nascido no Rio de Janeiro, combateu índios e foi camarista. Em 1619, recebeu sesmarias em Guaxandiba. Recebeu alvará de foros, escudeiro e cavaleiro fidalgo em 1642 por serviços prestados. Também foi provedor da Santa Casa de Misericórdia. BELCHIOR. Op. cit., p. 370-372.

${ }^{54}$ Lutou contra o gentio da terra. Fez grande doação aos beneditinos em 1646. Faleceu antes de 1660. BELCHIOR. Op. cit., p. 367-368.

55 Natural do Rio de Janeiro e morador de Cabo Frio. Dono de Currais em Parati. Morreu em 1648. BELCHIOR. Op. cit., p. 392-393.

${ }^{56}$ Nasceu em Portugal em 1584. Era Fidalgo da Casa Real e Cavaleiro da Ordem de Cristo. Em 1616, foi provedor das Minas da Repartição Sul. Foi capitão de cavalos e da fortaleza de São João, em 1620, alcaide-mor, em 1632, e governador interino, em 1633. Morreu em 1650. BELCHIOR. Op. cit., p. 489-492.

${ }^{57}$ Nasceu em Portugal. Era Cavaleiro da Casa Real e senhor de engenhos. Em 1608, combateu holandeses (piratas) em Cabo Frio. Morreu em 1648. BELCHIOR. Op. cit., p. 128-129.

${ }^{58}$ Foi um dos maiores "latifundiários" do Rio de Janeiro. Era fidalgo da Casa Real e capitão da Fortaleza de Santa Cruz. No final do século XVI, combateu goitacazes ao sul de Cabo Frio. Foi administrador das Minas entre 1621 e 1624. BELCHIOR. Op. cit., p. 412-414.

${ }^{59}$ É preciso destacar que três capitães - Duarte Correia Vasqueanes, Manuel Correia e Gonçalo Correia de Sá - possuíam laços de parentesco com Salvador Correia de Sá. Os dois capitães que mais se opuseram às divisões das terras, Miguel Ayres Maldonado e João de Castilho Pinto, também tinham vínculos de parentesco. Maldonado era casado com a filha de João de Castilho.
} 
grandes vantagens não só para Salvador, como também para os seus amigos e protegidos, tais como os jesuítas, os beneditinos e Pedro de Sousa Pereira”. ${ }^{60}$

A partir dessa data, os beneditinos aumentaram seu patrimônio na região dos Campos dos Goytacazes, fomentando a criação de gado. Suas terras, por conta da "escritura diabólica", como ficou conhecido o documento elaborado por Salvador Correia de Sá, sempre foram alvo de litígios.

No Livro de Acórdãos da Câmara Municipal, no dia 3 de abril de 1653, ${ }^{11}$ ficou registrado que frei Fernando de São Bento, como procurador da Ordem, fez requerimento aos oficiais da Câmara conclamando a "ajudar a defender os ditos seus currais e fazendas e a sustentar os ditos religiosos em sua posse”. ${ }^{62}$ Frei Fernando, natural de Pernambuco e professo na Bahia, cuidava das fazendas da Ordem na região de Campos dos Goytacazes, "a qual administrou com tanto zelo que Salvador Correia de Sá o constituiu também procurador e administrador das suas fazendas na mesma capitania". ${ }^{63}$ Um beneditino a serviço de um dos homens mais poderosos do Brasil demonstra o quanto os monges estavam estreitados com as "elites locais". Entretanto, o vínculo dos beneditinos com Salvador Correia de Sá oscilou muito, pois de aliado esse membro da elite tornou-se oponente dos monges em várias disputas por terras.

Além do pedido de proteção, frei Fernando informava que os beneditinos receberam a igreja de São Salvador de uma doação de Salvador Correia de Sá. $\mathrm{O}$ religioso se dizia vigário da dita igreja e ouvidor eclesiástico escolhido pelo prelado Antonio de Mariz Loureiro. Porém, havia sido mandado um novo vigário para a vila, pretendendo apossar-se da referida igreja. O beneditino, então, "requeria e pedia aos ditos oficiais da câmara que sustentassem a posse da dita igreja aos ditos religiosos, e que não consentissem que outro nenhum sacerdote, exceto padres de $\mathrm{S}$. Bento dissessem missas na dita igreja”. A disputa não era por uma igreja periférica, mas, sim, pela igreja mais importante da vila, a matriz. $\mathrm{O}$ controle da matriz garantia maior visibilidade e mais acesso ao domínio de um bom número de fiéis. Requerimentos como os feitos pelo procurador dos mon-

${ }^{60}$ BOXER (1973). Op. cit., p. 299.

${ }^{61} \mathrm{Tal}$ documento se encontra transcrito na integra em: FEYDIT, Julio. Subsídios para a história dos Campos dos Goytacazes desde os tempos coloniaes até a proclamação da República. Campos: J. Alvarenga \& Companhia, 1900. p. 48-49.

${ }^{62}$ Ibid., p. 49.

${ }^{63}$ Dietário/RJ, p. 133-134. 
ges assinalam a "fragilidade" das posses que eram adquiridas mediante doações naquela região, pois eram bens que os colocavam em disputas com outros membros das elites locais. ${ }^{64}$

Alguns anos depois, os beneditinos participaram novamente desses imbróglios na região. Porém, dessa vez, o principal monge envolvido foi frei Bernardo de Monteserrate, natural de Lisboa e com hábito tomado no mosteiro do Rio de Janeiro em $1646 .{ }^{65}$ Esse religioso, que faleceu em 1693, administrou as fazendas que a Ordem tinha nos Campos dos Goytacazes. Em 28 de setembro de 1674, foi solicitado pelo Conselho Ultramarino o seu afastamento do cargo e sua saída da região, por ter sido denunciado pelo ouvidor-geral Dr. André da Costa Moreira, sob a acusação de "que o dito padre acumulado de soldados e outras pessoas, expulsaram os moradores roubando-os só a fim de [os beneditinos] ficarem senhores daqueles campos". ${ }^{66}$ Cerca de dois anos depois, em 22 de julho de 1676, o abade frei Francisco do Rosário escreveu ao rei: "Pareceu-me representar a Vossa alteza com todo o serviço que este religioso, segundo as informações que dele há, procede como tal, faltando a sua pessoa na administração da fazenda que é muito grande, recebe a sua religião toda um irreparável dano." ${ }^{67}$ A petição termina solicitando o retorno de frei Bernardo aos currais de Campos, "por ser monge reformado e zeloso do patrimônio de São Bento". ${ }^{68}$

Em uma petição, também escrita em julho de 1676, fica claro o quanto os monges estavam vinculados às tensões dos poderes locais no processo de territorialização. Os assinantes de tal documento eram o reitor da Companhia de Jesus, o abade de São Bento, o general Salvador Correia de Sá, representado por seus

\footnotetext{
${ }^{64} \mathrm{O}$ cronista Julio Feydit afirma que o requerimento de frei Fernando possui uma assinatura apócrifa de um camarista e que o mesmo documento foi indeferido pela Câmara. Um dos documentos apócrifos mais interessantes sobre a posse de terras na região de Campos dos Goytacazes é o "Roteiro dos sete capitães", claramente escrito contra as atitudes de Salvador Correia de Sá e a favor dos capitães que se viram injustiçados pela redistribuição de terras. Cf. A descrição que fazem o capitão Miguel Aires Maldonado e o capitão José de Castilho Pinto e seus companheiros dos trabalhos e fadigas das suas vidas, que tiveram nas conquistas da capitania do Rio de Janeiro e de São Vicente, com a gentilidade e com os piratas nessa costa. Revista do Instituto Histórico e Geográfico do Brasil. Rio de Janeiro: Imprensa Nacional, 1893. t. LVI.
}

${ }^{65}$ ENDRES, D. José Lohr. A Ordem de São Bento no Brasil quando província (1582-1827). Salvador: Beneditina, 1980. p. 173.

${ }^{66}$ IEB/USP-Col. ML, 19.31, f. 2.

${ }^{67}$ Ibid., f. 1 .

${ }^{68}$ Ibid., f. 3. 
procuradores, o sargento-mor Martim Correa Vasqueanes, o capitão Cristóvão Lopes Leitão, a viúva do capitão Manuel Caldeira Soares, Gregório Dultra Leão, João Gouveia Silva, "e os mais senhores e possuidores das terras chamadas Paraíba e Goytacazes". ${ }^{69}$ Os solicitantes constituíam parte considerável dos "principais da terra" que estavam envolvidos na redistribuição territorial que Salvador de Sá empreendera anos antes. O teor da petição expõe as pretensões de posse que estavam em constante litígio. Os "principais", tentando reafirmar a legitimação de seus bens, alterando inclusive o tempo de ocupação, informavam, que estavam da posse pacífica das terras por mais de 50 anos. ${ }^{70}$

O abade, o reitor, Salvador Correia de Sá e seus companheiros denunciavam que vinham da Bahia e do Espírito Santo para os ditos Campos

várias pessoas pela maior parte homiziados, homens foragidos e outra mais gente vagabunda que vão se situando na dita terra sendo já passante ou mais de cinquenta pessoas que todos vivem das mesmas fazendas, gado e roçarias deles suplicantes indo também fazendo engenhos de aguardente. ${ }^{71}$

Era uma disputa entre "bandos", algo notado com recorrência nas contendas por governança, mas pouco explorado pela historiografia em processos de territorialização. Na solução apontada, os reclamantes destacaram a importância econômica da região e o serviço que prestavam nessa ocupação, e enfatizaram que tinham de se livrar dos "intrusos", pois estes davam "Grande perda e confusão nas ditas suas propriedades de que redunda também grande desserviço a sua Alteza por vir a ser um valhacouto a dita habitação de homens perdidos", dando prejuízo aos engenhos e boiadas da região. ${ }^{72} \mathrm{O}$ documento termina com um pedido por justiça, com anuência para os solicitantes poderem desterrar, aplicar multa e degredar para Angola seus oponentes.

Nas disputas por terras, mudanças geracionais transformaram os beneditinos de aliados em desafetos da família Sá, pelo menos de um integrante da importante linhagem, o visconde de Asseca, Diogo Correia de Sá e Benevides Velasco. Em 1683, enquanto Salvador Correia de Sá estava em Portugal, o visconde fez

\footnotetext{
${ }^{69}$ Ibid., f. 5.

${ }^{70} \mathrm{Id}$.

${ }^{71}$ Ibid., f. 10.

${ }^{72}$ Ibid., f. 11.
} 
uma queixa ao rei informando que os beneditinos, unidos a outros senhores de engenho,

"roubam os escravos, e fazendas daqueles moradores e dele suplicante fazendo-se tão poderosa a força de armas que já com gente de sua facção e soldados, expulsaram os moradores dos Goitacazes, roubando-os, destruindo-os e fazendo-se violências e tiranias, senhores daqueles campos. ${ }^{73}$

Os beneditinos demonstravam o quanto tinham se tornado um poder local. Ao lado do visconde estava posicionado um representante do clero, o vigário Francisco Gomes Sardinha, responsável pela capitania da Paraíba do Sul e Cabo de São Thomé, com matriz na vila de S. Salvador, a mesma que, em 1653, foi disputada pelo monge frei Fernando de São Bento. A queixa incidia especificamente sobre três monges, frei Bernardo de Monteserrate, frei Sebastião de Jesus e o donato frei André do Rozário, que, de acordo com o vigário, assistiam "na dita capitania em currais do seu Convento que tem no Rio de Janeiro, fora da clausura mais de oitenta léguas". ${ }^{74}$

O padre vigário informava que, em 18 de maio de 1682, a pedido do capitão José de Barcelos Machado, ia a confessar um doente e batizar uma criança quando, a meio caminho da localidade conhecida por Queribas, foi emboscado por frei André, frei Sebastião e frei Bernardo, que o constrangeram a assinar um documento para ser solto um escravo do licenciado Clemente Martins de Matos que andava foragido por nome João do Rosário. Além do próprio capitão José Barcelos Machado, o padre tomou como testemunhas Manuel Cazado Tourinho, José de Barcelos Machado, o Moço, Gaspar de Barcelos Machado, Luiz Mendes da Costa e o capitão Antonio Rodrigues Moreira. ${ }^{75}$

Enumerando alguns escravos roubados de seus senhores, como um mulato de Manoel Machado e um negro de João Machado, afirmava que eram "os ditos frades useiros e vizeiros a terem negros alheios e se servirem deles fazendo das fazendas da sua religião valhacoutos de negros criminosos com um que tem por nome Garcia, com quatro mortes". ${ }^{76}$

\footnotetext{
${ }^{73}$ IEB/USP-COL. ML, 19.32. f. 1.

${ }^{74}$ Ibid., f. 4.

${ }^{75}$ Ibid.., f. 5.

${ }^{76} \mathrm{Id}$.
} 
Havia informação de que o trio cativara uma mulata de nome Paula, "livre por lei”, para constrangê-la a casar violentamente com um negro cativo de sua religião, e que "o dito frei André tem tirado violentamente outra mulata cativa de Catharina de Souza, "uma pobre viúva com mais de dez filhinhas e a tomou para o seu convento e a casou com um mulato escravo da sua religião, por nome Ignácio e se estavam servindo dela sem nenhum temor de Deus'"' 77

O acusado, frei Bernardo, já havia se envolvido em querelas na região, como salientamos. Outro envolvido, frei Sebastião de Jesus, era nascido no Rio de Janeiro e havia tomado hábito na Bahia, mas infelizmente temos pouquíssimos dados sobre ele. ${ }^{78}$ Quanto ao mais detratado nas queixas, sendo inclusive considerado o mais violento e impulsivo, frei André do Rosário, sabemos que era irmão donato, nascido em Portugal e com hábito tomado no Rio de Janeiro em 8 de janeiro de $1667 .{ }^{79}$ Esse monge, falecido em 31 de maio de 1687, deixou opinião de seu temperamento entre seus irmãos de hábito que coaduna com o comportamento apontado pelo vigário. Disseram os monges que frei André "era robusto, ágil, de ânimo intrépido e de forças mais que ordinárias, e por isso foi mandado governar a fazenda dos Campos, aonde satisfez com as obrigações de seu estado e do seu emprego". ${ }^{80}$ Deixou escapar um monge cronista que, para administrar fazendas em local de constante tensão, era preciso mais do que mera desenvoltura com a contabilidade e habilidade no beneficiamento e trato da escravaria, era imprescindível ser destemido e ter forças suficientes para lidar com um "bando".

$\mathrm{Na}$ continuidade de sua correspondência, o vigário demonstra que sabia bem como atingir seus desafetos, indo além de queixas sobre querelas locais e o uso de braço escravo armado. ${ }^{81} \mathrm{O}$ argumento golpeava não somente alguns monges em particular, mas a instituição como um todo, pois o padre afiançava que as terras eram conquistadas com violência, e a Fazenda Real era quem arcava com grande prejuízo, pois os religiosos não pagavam dízimos e possuíam bens de raiz sem

\footnotetext{
${ }^{77}$ Ibid.., f. 12.

${ }^{78}$ Dietário RJ, p. 145.

${ }^{79}$ Ibid.., p. 139.

${ }^{80}$ Ibid.., p. 139.

${ }^{81}$ As queixas sobre o fato de os beneditinos dominarem grupos de escravos armados foram constantes em todo o século XVIII. Os próprios religiosos admitiram tal costume, positivando-o no caso do auxílio que deram na tentativa de conter a incursão francesa ao Rio de Janeiro, em 1711.
} 
as necessárias licenças da Coroa. ${ }^{82} \mathrm{~A}$ denúncia reiterava questões que pesavam sobre os religiosos do clero regular e que sempre vinham à tona nos momentos de conflito.

Não temos informações sobre o desenrolar de tal contenda, mas, pela trajetória dos monges denunciados e pela continuidade dos beneditinos nos Campos dos Goytacazes, é possível deduzir que não teve maiores consequências para os religiosos regulares, já que o dito vigário foi afastado de seu cargo em 1689. De acordo com Alberto Lamego, isso ocorreu porque "a câmara, composta de pessoas que dependiam da Ordem de S. Bento, era o espelho onde se refletiam os desejos desta". ${ }^{83}$ Além disso, é preciso levar em consideração que o presidente do mosteiro no momento das denúncias e depois ocupante de cargos importantes na Ordem era frei Cristóvão de Cristo, "filho dos melhores da terra" Cristóvão Lopes Leitão e Mariana Soberal.

Em 1679, o pai do abade era dono de dois terços da "fábrica de baleias", tinha sido oficial de justiça e juiz de fora. Em 9 de dezembro 1688, ele foi responsável pela abertura do segundo livro de tombo do mosteiro. Ele e sua esposa, Mariana de Soberal, eram considerados "ambos nobres, ricos e virtuosos" ${ }^{84}$ Cristóvão Lopes era descendente de um fidalgo da Casa Real, Domingos Leitão, que acompanhara o governador Mem de Sá. ${ }^{85} \mathrm{O}$ capitão Cristóvão Lopes, por meio de sua prima, Cecília de Siqueira, era aparentado do capitão Manuel Fernandes Franco. Quando deixou terras na Ilha do Governador para o mosteiro, Manuel Fernandes tinha como testamenteiro Cristóvão Lopes. Essa família extensa é reconhecida por João Fragoso como parte da "elite" do Rio de Janeiro colonial. ${ }^{86}$ Portanto, o abade Cristóvão de Cristo não era um monge minhoto com poucos recursos familiares na América portuguesa. O religioso denunciado pelo vigário já fazia parte de uma geração de monges que possuíam vínculos de parentesco com os "principais da terra". Esse vínculo era de mão dupla: os dois capitães também se ligavam aos beneditinos de outra maneira, pois eram proprietários das duas

\footnotetext{
${ }^{82}$ IEB/USP-COL. ML, 19.32. f. 10.

${ }^{83}$ LAMEGO, Alberto. A terra Goitacá à luz de documentos inéditos. Bruxelas: S/E, 1920. livro II, p. 165.

${ }^{84}$ Dietário/RJ, p. 148.

${ }^{85}$ LISBOA, Balthasar da Silva. Anais do Rio de Janeiro. Rio de Janeiro: Tip. Imp. e Constitucional de Seignot-Plancher, 1835. v. I, p. 90.

${ }^{86}$ FRAGOSO (2000). Op. cit., p. 45-122.
} 
principais capelas laterais na igreja do mosteiro: a de São Cristóvão foi vendida ao capitão Cristóvão Lopes Leitão em $1671,{ }^{87}$ enquanto a de Nossa Senhora da Conceição foi vendida ao capitão Manuel Fernandes Franco em 1689.88

\section{Inserções material e imaterial}

Entrar em conflito com os monges a partir da segunda metade do século XVII - como o ocorrido em Campos dos Goytacazes - era ir de encontro a uma família cujos vínculos cada vez mais se estreitavam com membros de elites locais. Enfrentar a Ordem era mais do que encarar uma instituição religiosa, o que por si só configurava certa ousadia. Era, sobretudo, entrar em atrito com um foco de poder que dinamizava relações além de suas cercas. Em suma, era afrontar senhores de engenhos, gados e terras. Senhores de almas. Família poderosa.

Diferentemente dos jesuítas, que aplicaram parte dos seus recursos na própria empresa missionária, e das ordens mendicantes, que não possuíram engenhos e imensa escravaria, os beneditinos reverteram seus ganhos sobretudo para o próprio engrandecimento de suas casas, com construções arquitetônicas bemelaboradas, mesa farta, diversos empregados pagos, compra de cativos, beneficiamento de engenhos e aquisição de imóveis e terras. O padrão de riqueza das casas beneditinas, incluindo seu comportamento de consumo, sobrepujava muitos senhores de diversas regiões. A manutenção de seu status era preocupação constante que transparece nas memórias de suas rotinas administrativas, na marca arquitetônica de seus mosteiros e igrejas e no uso de meios coercivos. Os monges montaram bibliotecas que eram verdadeiras ilhas de conhecimento nos trópicos. Enalteciam-se pelo saber, elogiando o grau de estudos de seus membros, outro aspecto distintivo sempre lembrado nas memórias dos religiosos falecidos. As casas beneditinas eram focos de poder, contando com foro privilegiado, vínculos com elites locais, inclusão de membros das "famílias das melhores da terra", além de deterem parte do monopólio de disciplinamento moral e espiritual da América portuguesa. Nos mosteiros, pelo menos de acordo com o sistema normativo, pessoas consideradas de "nação infecta" não eram aceitas. Uma seleção

\footnotetext{
${ }^{87}$ SILVA-NIGRA (1950). Op. cit., p. $44^{\star}-45^{\star}$.

${ }^{88}$ II Livro do Tombo/RJ. Op. cit., f. 2-4.
} 
era realizada, mesmo com brechas. Os monges faziam parte de uma instituição que detinha muito prestígio em Portugal.

A somatória desses aspectos fornecia aos beneditinos arcabouço para se considerarem melhores do que os que habitavam fora das cercas monásticas, e, concomitantemente, serem vistos dessa forma por muitos vassalos, inclusive membros de outras ordens religiosas. A instituição acumulou, além de propriedades, um precioso bem intangível: reputação. A esfera de ação dos religiosos ia muito além dos limites de seus claustros. Por tais características, as casas beneditinas atuavam como elites locais, sobretudo as mais relevantes na hierarquia eclesiástica, como a aqui analisada. Comportamento institucional que ocasionou embates com autoridades e governanças, na América portuguesa e no Reino. 